\title{
The Relationship between Reading Strategies and Reading Achievement of the EFL Students
}

\section{Leonardus Par}

Universitas Negeri Malang, East Java \& Universitas Katolik Indonesia St. Paulus

Ruteng, Flores, Indonesia, parma101011@yahoo.com

The purpose of the study is to discover the relationship between the use of reading strategies and reading achievement among EFL students in Indonesia. It involves 56 EFL university students majoring in English by providing questionnaire of Survey of Reading Strategies (SORS) in order to know the use of reading strategies; and Reading Comprehension Test (RCT) to measure their reading achievement or reading ability. The reading strategies were classified into Global, Problem Solving, and Supporting strategies. Meanwhile, the RCT was 35 multiple choice test items. The findings of the study reveal that (1) the EFL students are active strategies users; they prefer problem-solving strategies more than global and supporting strategies; (2) there is a significant correlation between the overall reading strategy use and the students reading achievement; (3) the problem-solving strategies are the predictive factors of the students' reading achievement. In conclusion, the more the students apply the problem-solving strategies in reading activities, the better their ability to understanding the texts.

Keywords: reading strategy, reading achievement, reading skills, EFL students, correlational study

\section{INTRODUCTION}

Training students to read effectively is the main concern of the teachers and researchers in the field of EFL to ensure success in learning. Reading is the most emphasized skill among other language skills in EFL setting. According to Anderson (2003), reading is viewed as an essential skill for learners of English and it is the most important skill to master in order to guarantee success in learning. Similarly, Khamkhong (2018) states that to be effective and successful in class, students are demanded to read extensively and effectively for knowledge and information from textbooks, research articles, and other valuable sources. Reading is an active and interactive process of constructing meaning that involves the reader and the reading material. In this process, a reader employs certain reading strategies to effectively and efficiently grasp the content of the reading materials or texts. Skilled readers engage in purposeful strategies to support

Citation: Par, L. (2020). The Relationship between Reading Strategies and Reading Achievement of the EFL Students. International Journal of Instruction, 13(2), 223-238. https://doi.org/10.29333/iji.2020.13216a 
understanding and monitor meaning, (Denton et al., 2015). Thus, in order to be successful in learning, the EFL students should read extensively and apply certain effective reading strategies to build the meaning of the text.

Numerous studies have been conducted to investigate the awareness of the use of reading strategies (Chen \& Chen, 2015; Poole, 2013; Amiryousefi, Dastjerdi \& Tavakoli, 2012; Madhumathi \& Ghosh, 2012; Genc, 2011; Poole, 2009; Mokhtari \& Sheorey, 2002), cognitive reading strategies by EFL students (Ozek and Civelek, 2006), and metacognitive reading strategy (Ahmadian \& Pasand, 2017; Pinninti, 2016; Alsheikh \& Mokhtari, 2011; Iwai, Filce \& Ramp, 2011; Zhang \& Wu, 2009; Mokhtari \& Reichard, 2002) employed by the learners during reading academic texts. These include the association with the students reading achievement or reading comprehension (Shang, 2018; Muijselaar, et al., 2017; Kim, 2016; Huang \& Nisbet, 2014, Hong-Nam, 2014; Saeedeh, 2013), reading proficiency, grade level and gender (Denton et al., 2015). The studies discover that the students employ certain reading strategy in their reading activities to construct the meaning of the text, and their use of reading strategy has a relationship with their reading achievement and reading proficiency. The learners are active readers when they are reading a text because they are employing certain ways to comprehend the text. The previous findings confirm the theory that comprehending a text is strategic (Duffy, 2009: 17) in which readers use certain ways to help them figure out the content of the texts.

Successful readers usually apply a certain reading strategy when reading a text. Gebhard (2009: 199) points out some strategies which are usually employed by successful readers, namely skipping the words not known, predicting the meaning, guessing meaning of unfamiliar words from context, avoiding constant translation, looking for cognates, having knowledge about the topic, drawing inferences from the topic, reading things of interests, studying pictures and illustrations, and purposefully rereading to check comprehension. These reading strategies are useful for the readers in order to effectively comprehend the reading texts. By employing certain effective strategies in reading, the students will easily and efficiently grasp the content of the texts.

Grounding on the some reading strategies proposed by Gebhard (2009), a study conducted by Ozek and Civelek (2006) exposes the different reading strategy use, according to the reading phases or stages, such as pre-reading, whilst-reading, and postreading among different levels of students: first year and fourth year students in ELT Department. The findings of the study reveal that for the pre-reading strategies, highproficient learners are better in using pictures/illustrations and in skimming comparing to the poor ones, low-proficient readers. For the while-reading phase, the high-proficient learners perform better than low-proficient students in guessing the meaning of a word, skipping words, not translating word for word, visualizing events, and guessing the assimilating the text. Last but not least, from the post-reading strategies, it is found that the excellent subjects were better than the poor ones in summarizing the main ideas of the texts.

In contrast to research conducted by Ozek and Civelek (2006) who specifically investigate the reading strategy use in pre-reading, while-reading, and post-reading 
strategies, Mokhtari \& Sheorey (2002) measured the students' metacognitive awareness and perceived use of reading strategies while reading texts using Survey of Reading Strategies (SORS). This SORS was developed based on three categories of reading strategies, namely global reading strategies (GLOB), Problem-solving strategies (PROB), and Support strategies (SUP). Global strategies refer to those that deliberately planned to monitor the reading process, such as previewing and predicting. Problemsolving strategies are actions that readers use to better process difficult texts by guessing the word meaning from context clues and visualization of the text content. At last, support strategies are those basic categories which aid the readers to comprehend the text by using a dictionary, taking notes, underlining, or highlighting textual information.

Basing on the reading strategy category developed by Mokhtari \& Sheorey (2002), a number of studies have been conducted to know the students' reading strategy use, to identify which reading strategy categories are the most frequently used, and to discover the reading strategy categories which are used as a powerful predictor to student reading proficiency in ESL setting (Huang \& Nisbet, 2014; Iwai, Filce \& Ramp, 2011; Madhumathi \& Ghosh, 2012; Barrot, 2016); in EFL setting (Zhang \& Wu, 2009; Saeedeh, 2013; Genc, 2011; Chen \& Chen, 2015; and investigate reading strategies used across gender (Poole, 2009); Ahmadian, 2017). Despite the result of these studies are fluctuates, they, generally, provide identical findings that the ESL and EFL students are strategic and skilful readers.

More specifically, studies conducted by Chen \& Chen, (2015), Huang \& Nisbet (2014), Madhumathi \& Ghosh (2012), Zhang \& Wu (2009), and Poole (2009) expose that the ESL/EFL students are active reading strategy users. Besides, among the three reading categories, the studies reveal different findings on the students' preferences which they most frequently used while reading. Huang \& Nisbet (2014) and Madhumathi \& Ghosh (2012) uncover that students prefer to problem-solving strategies more than other strategies. These findings contrast to Chen \& Chen (2015) and Barrot (2016) who find that the students had a preference for global reading strategies, followed by problemsolving and support strategies. Moreover, the studies also show that there is a relationship between the students' use of reading strategies and their reading proficiency (Barrot, 2016); Huang \& Nisbet, 2014; Saeedeh, 2013; Madhumathi \& Ghosh, 2012). Moreover, a study conducted by Saeedeh (2013) confirms the theory proposed by Gebhard (2000) indicating a statistically significant and positive relationship between EFL learners' overall use of reading strategies and their reading comprehension test scores. The result of the study indicates that the successful readers (learners) who apply reading strategies obtain good scores in reading comprehension tests, comparing to their low-ability readers. Yet, the types of the reading strategy used by the learners can predict their reading ability or academic achievement or success in learning.

As seen from the previous research findings which reveal the strategies used by the learners in reading and its relationship with their reading proficiency, the investigation of the students' ways of reading and knowing its relationships with their reading ability or achievement is still relevant to conduct. This is because every student in different gender, age, learning styles, and culture, education level, language proficiency level, reading proficiency level are unique in their way of learning, especially in reading. 
Sadeghi, Kasim, Tan, and Abdullah (2012) specify that different personality types and/or traits of the learners contribute to the different success of academic learning at schools. This indicates that every individual student has his/her unique way of learning and reading. Accordingly, it deserves to explore more deeply about the students' reading strategies use and its correlation to their reading achievement in EFL site.

Regardless of a lot of studies in identifying the strategies used by the learners in reading, very little research showing the most frequently reading strategies used in reading by the EFL students, indicating the relationship between the use of reading strategies with their reading achievement, and identifying the types of reading strategy categories which are useful predictors of the reading achievement scores. The students' reading achievement is related to their ability or skill in determining the content of the texts based on reading micro-skills proposed by the experts at the Education Testing Service (ETS) who design the Test of English as a Foreign Language (TOEFL), such as understanding main idea, understanding supporting ideas/details, understanding organization of the text, understanding implied details, understanding word meaning, understanding pronoun reference, and understanding the writer's tone of writing (Sulistyo, 2015). These reading micro-skills are covered in the reading comprehension test (RCT) used in the study. These reading skills are rarely covered in the reading comprehension test and their association with the use of reading strategies in the previous studies. Accordingly, the current study is conducted under the following questions.

1. What reading strategies do EFL learners use most frequently when reading?

2. Does the use of reading strategy categories correlate with the reading achievement?

3. Which reading strategy categories are useful predictors of reading achievement score?

\section{LITERATURE REVIEW}

\section{Reading Strategies and Reading Skills}

Reading strategies and reading skills are two technical terms which are used frequently in the literature and classrooms. Experts and researchers in the reading area show that reading strategies and reading skills are different. In a search for clarifying the differences between reading strategies and reading skills, Afflerbach, Pearson, \& Paris (2008) propose that reading strategies are "deliberate, goal-directed attempts to control and modify the reader's efforts to decode text, understand words, and construct meanings of the text. Reading skills are automatic actions that result in decoding and comprehension with speed, efficiency, and fluency and usually occur without awareness of the components or control involved". Accordingly, strategies are deliberately controlled processes; skills, in contrast, are automatic processes.

Reading skills are cognitive abilities, part of the generalized reading process, which a person is able to deploy when interacting with written texts (Urquhart \& Weir as quoted by Manoli \& Papadopoulou, 2012). Thus, reading skills are the abilities that are owned by a reader to construct the meaning of the text. In constructing the meaning of a text, a reader needs a controlled process which empowers the process. That's why reading is an active process and a purposeful activity which requires active involvement from the 
reader in comprehending the texts. Dole et al (1991) point out that strategies are conscious, intentional, deliberate, and flexible plans emphasizing reasoning that reader applies and adapt to a variety of texts in order to construct meaning from texts. Strategies imply metacognitive awareness which good readers make decisions about a strategy to use, when to use it and how to adapt it to a particular text when construct and reconstruct the meaning from the text. In summary, strategies are deliberate plans readers use flexible and adaptively in reconstructing the texts. They are metacognitive repertoires. Skills, in contrast, are automatic processes readers overlearning that result from reading activities. They are cognitive abilities.

There are three categories of reading strategies proposed by Mokhtari \& Sheorey, (2002), namely global reading strategies (GLOB), Problem-solving strategies (PROB), and Support strategies (SUP). Global reading strategies are those intentional, carefully planned techniques by which learners monitor or manage their reading; such as having a purpose in mind, previewing the text as to its length and organization, or using typographical aids and tables and figures. Problem-solving strategies, other reading strategy categories, are the actions and procedures that readers use while working directly with the text. These are localized, focused techniques used when problems develop in understanding textual information; examples are adjusting one's speed of reading when the materials become difficult or easy, guessing the meaning of unknown words, and rereading the text to improve comprehension. The last category, support strategies are basic support mechanisms intended to aid the reader in comprehending the text such as using a dictionary, taking notes, underlining, or highlighting textual information. These are the strategies that the students or readers use to help them comprehend, construct, and reconstruct the meaning of the text.

Though reading strategies and reading skills are diverse, they are correlated as reading strategies may cultivate reading skills through frequent practice and use. Shih \& Huang (2018) state that reading comprehension (skill) is believed to take place at the metacognitive level where planning, monitoring, and evaluating are involved. Metacognitive strategies carry out an executive function over cognitive strategies, in which, in turn, impact reading test performance. To support this claim, numerous studies have been conducted to investigate the relationship between reading strategy use and reading ability (Shang, 2018; Muijselaar, et al., 2017; Kim, 2016; Huang \& Nisbet, 2014, Hong-Nam, 2014; Saeedeh, 2013). The studies indicate the positive correlation between the two observed variables. The students, who have applied reading strategy frequently in their reading activities, perform better in their reading test. Accordingly, when the students use the reading strategies regularly, their reading skills will be improved.

\section{METHOD}

\section{The Participants}

This study aims at finding out the relationship between the use of reading strategies and reading achievement among the Indonesian EFL students. Accordingly, the research type was a correlational study (Ary, Jacobs, Sorensen, and Razavieh, 2010) which is typically used to assess the relationships among two or more variables in a single group. 
To this end, there were 56 students in the sixth semester who had taken and passed reading courses at the English Department in a state university in Indonesia got involved as the participants of the study. Their age ranged from 21 to 23 . A non-probability convenience sampling (Dornyei, 2007, Creswell, 2012) was applied for the selection of the participants as they were easy to access, available at the time of collecting the data, willing to involve in the study, and they were typical EFL students. Moreover the participants were met with the criteria of the objective of the study, which is they have taken reading courses in which they had been provided reading various materials for academic studies ranging from course books, journal articles, to research papers; and had been trained to employ certain reading strategies in building the meaning from the reading materials. As reading is one of the main language skills which is a compulsory subject learned by the EFL learners, the students as the participants of the study were hoped to have experienced and read a large number of English texts which helped them develop their language acquisition and learning. Also, in an EFL setting at the university level, reading courses were delivered to students to promote their habit and independence of reading inside and outside of the classroom which demands them to employ effective reading strategies to reconstruct the content of the texts.

\section{The Instrument}

In the current study, the students were given a questionnaire of Survey of Reading Strategies (SORS) which was firstly developed by Mokhtari and Sheorey (2002) in order to identify the use of reading strategies. The internal estimate reliability of the SORS instrument using Cronbach's coefficient alpha was .89 , and it is valid and reliable for use to adult and non-native English speakers.

The SORS consists of 3 items with three subscales: Global Reading Strategies (GLOB) consisting 13 items, Problem Solving Strategies (PROB) consisting 8 items, and Support Strategies (SUP) consisting 9 items. In the SORS, the students can reflect their own reading strategy use by marking the five Likert type scale based on each statement, like 'I always do this' (5), 'I usually do this' (4), 'I sometimes do this' (3), 'I do this only occasionally' (2), and 'I never do this' (1).

Moreover, in measuring the students reading achievement, they were given the Reading Comprehension Test (RCT). The RCT consisted of 35 multiple choice items. Before using the RCT in the study, it was firstly piloted to test its validity and reliability to a group of students who have similar characteristics of the sample. Accordingly, the reliability of RCT using Cronbach's coefficient alpha was .88.

\section{Data Analysis}

The data that were collected from SORS and CRT were analysed by applying descriptive statistics which provides mean, and standard deviation scores of the overall use of reading strategy: Global, Support, and Problem-Solving strategies. The descriptive statistics functions to identify the overall use of reading strategies. The level of the overall reading strategy use is interpreted using the standard criterion proposed by Oxford and Burry-Stock (1995) that is a mean of 3.5 or higher is considered as high, a mean score of 2.5 to 3.4 is termed as moderate, and it is low when the mean score is 2.4 or lower (Oxford \& Burry-stock, 1995). Furthermore, the detail means scores of each 
reading strategy employed by the students also were computed by using the descriptive statistics.

To know the correlation between the use of reading strategies and reading achievement among the EFL students, the Pearson product-moment correlation coefficient was applied. Interpreting the strength of the correlation was using the guide suggested by Evans (1996) who indicates the level of the correlation into $0.00-0.19$ (very weak), $0.20-0.39$ (weak), $0.40-0.59$ (moderate), $0.60-0.79$ (strong), and $0.80-1.0$ (very strong). Meanwhile, multiple regression computation was taken in order to determine the reading strategy categories which were useful predictors of the students' reading achievement scores. The data were mainly computed by using the Statistical Package for the Social Science (SPSS) version 24.

\section{FINDINGS}

The findings of the study related to data or information obtained from the two instruments, such as SORS and RCT. The data were presented in order to answer the research questions initially proposed.

\section{The Reading Strategies Which Are Used Most Frequently}

The first research question states, "What reading strategies do EFL learners use most frequently when reading?" This research question requires data about the most frequency of the strategy use employed by EFL students while reading. From the result of the descriptive statistics computation, the students' overall reading strategy use was considered as high users by looking at the mean score that is 3.54 and the standard deviation is .58 (Table 1). The mean score of 3.54 is considered as high is based on the criteria proposed by Oxford and Burry-Stock (1995).

Table 1

Descriptive Statistics of the Overall Reading Strategy Use

\begin{tabular}{llll}
\hline Descriptive Statistics & & & \\
\hline & $\mathrm{N}$ & Mean & Std. Deviation \\
\hline Overall Reading Strategy Use & 56 & 3.54 & .58 \\
\hline
\end{tabular}

Table 1 displays the result of analysis of the overall reading strategies used by the EFL students in which the average score is 3.54. This result indicates that EFL students are highly active users of reading strategies in reading activities.

Furthermore, the most frequently reading strategy categories used by the students was problem solving $(\mathrm{M}=3.80, \mathrm{SD}=.37)$, followed by global strategies $(\mathrm{M}=3.46, \mathrm{SD}=$ .33). The least favored strategy by the students was 'support strategies (SUP)' ( $\mathrm{M}=$ $3.43, \mathrm{SD}=.22$ ). The related data is presented in Table 2 .

Table 2

Results of Descriptive Statistics for the Reading Strategy Categories

Descriptive Statistics

\begin{tabular}{llll}
\hline Strategy Categories & Mean & Rank & Std. Deviation \\
\hline Problem Solving Strategies & 3.80 & 1 & .37 \\
Global Strategies & 3.46 & 2 & .33 \\
Support Strategies & 3.43 & 3 & .22 \\
\hline
\end{tabular}


Table 2 depicts the rank of the reading strategy categories which is the most frequently employed by the EFL students in the study. It is obviously presented that 'problemsolving strategies (PROB) are the most frequently reading strategy categories employed by the EFL students. Besides, 'global strategies (GLOB)' are the second favorite reading strategy categories used by the students in constructing the meaning of the texts. The least favorite reading strategies is 'support strategies (SUP)' due to it has the lowest mean score that is 3.43 .

Moreover, from the distribution of the strategy use (see Table 3), it is obviously seen that the EFL students were at moderate (mean score of 2.5 to 3.4) to high (mean score 3.5 or above) use of the reading strategy. From the overall reading strategy, there were $16(53.33 \%)$ reading strategies considered as highly used by the students; and 14 (46.67\%) strategies were reflected as moderate usage. Out of 16 reading strategies which were highly employed by the students, there was 7 global reading strategies category, followed by 6 and 3 problem-solving and support reading strategies respectively.

Table 3

Distribution of the Strategy Use

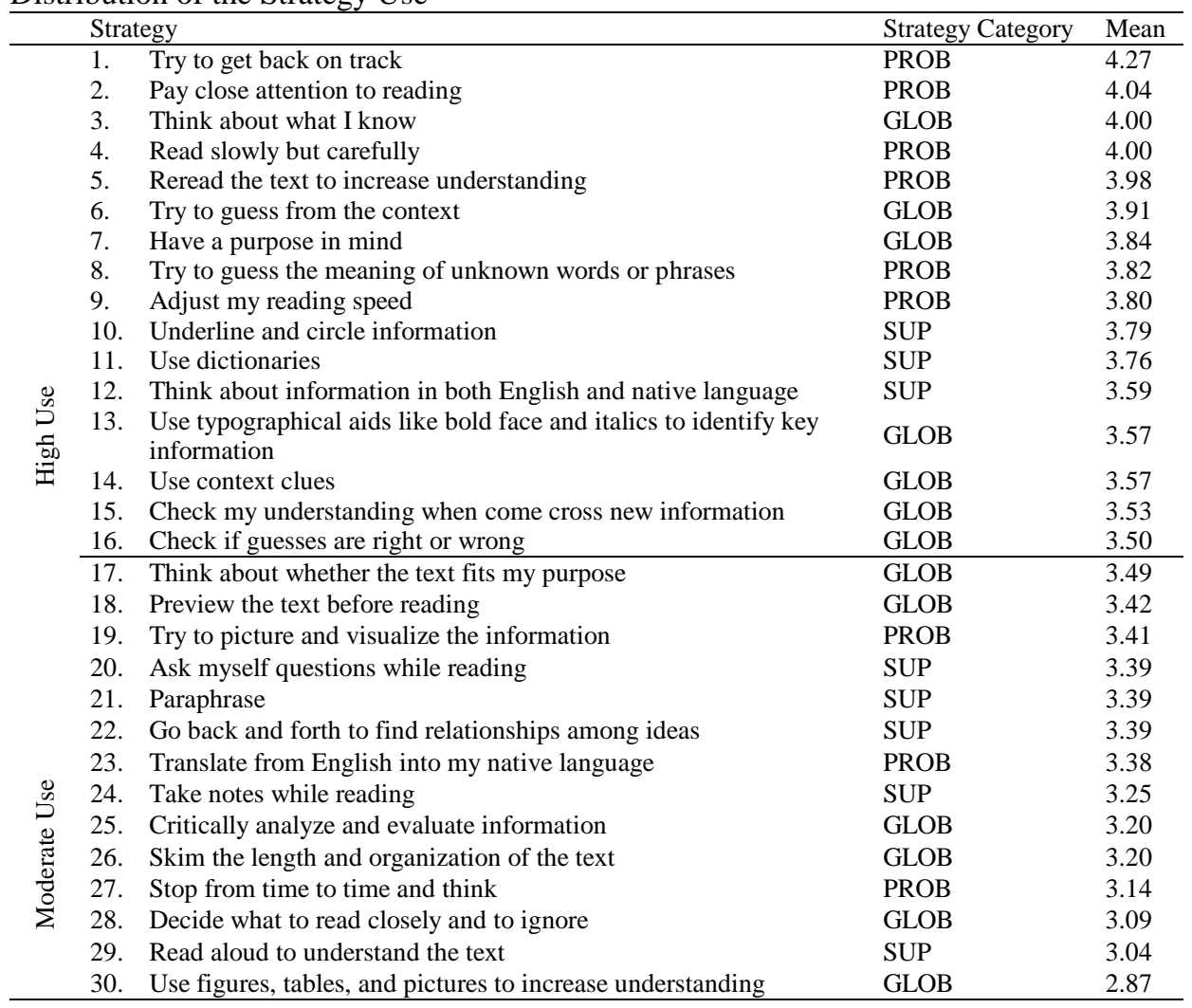


Table 3 portrays the distribution of the use of reading strategies by the students in the study. It is apparently seen that the EFL students are at the moderate and high users of reading strategies in reading activities. The mean scores range from 2.87 to 4.27 . The lowest average score, which is 2.87 is the global strategies (GLOB) category, item thirty (3): "Use figures, tables, and pictures to increase understanding". Meanwhile, the highest average score is 4.27 which is the problem-solving strategies (PROB) item one (1): "Try to get back on track".

\section{The Relationship between the Use of Reading Strategy Categories and Reading} Achievement

The second research question concerns the finding of the relationship between the EFL students' overall use of reading strategy categories and their reading achievement. Table 4 displays the result of calculating the Pearson Product moment correlation of the data in the study. The statistical computation revealed that the value of the Pearson correlation of SORS toward reading was .516 or .52 indicating the moderate correlation level of the variables. This means that there was a moderate relationship between the reading strategies use and the reading achievement among the EFL students. This relationship indicated that the change in reading strategy was moderately correlated with change in the reading achievement.

Table 4

The Scores of the Pearson Product Moment Correlation

\begin{tabular}{llll}
\hline Correlations & & & \\
\hline & & Reading & SORS \\
\hline \multirow{2}{*}{ Reading } & Pearson Correlation & 1 & $.516^{* * *}$ \\
& Sig. (2-tailed) & & .000 \\
& $\mathrm{~N}$ & 56 & 56 \\
\hline \multirow{3}{*}{ SORS } & Pearson Correlation & $.516^{* * *}$ & 1 \\
& Sig. (2-tailed) & .000 & \\
& $\mathrm{~N}$ & 56 & 56 \\
\hline
\end{tabular}

**. Correlation is significant at the 0.01 level (2-tailed).

Table 4 shows the scores of the Pearson Product Moment correlation between the use of reading strategies and reading achievement. It is depicted that the value of the correlation between SORS with reading achievement is .516 or .52, and this correlational value is classified as moderate. Despite the moderate correlation, it observes that the Sig. (2-tailed) the value is .000 , and this value is less than 0.01 ; because of this, it could be concluded that there was a statistically significant correlation between the use of reading strategies and reading achievement among the EFL students.

\section{The Reading Strategy Categories which are Useful Predictors of the Students Reading Achievement}

Research question number 3 was related to identifying the reading strategy categories which were useful predictors of reading achievement scores of the students. It is clearly provided in Table 4 that the value of each global, support and problem-solving strategies for reading achievement is $.113, .033$, and .888 respectively. Among the three value of the reading strategy categories, the problem-solving categories' value was 
bigger than the other two (global and support categories) values. This indicates that the most predictive reading strategy category toward reading achievement of the students was problem-solving categories. In addition, the predictive value of the problem-solving reading strategy categories was significant at the point of .002 which was less than .05 . It suggests that there was a statistically significant correlation between the problemsolving reading strategy categories and reading achievement of the students.

Table 5

The Value of the Global, Support, and Problem Solving Strategies toward Reading Achievement

\begin{tabular}{llllll}
\hline & & Reading & Glob & Sup & Prob \\
\hline \multirow{4}{*}{ Pearson Correlation } & Reading & 1.000 & .113 & .033 & .883 \\
& Glob & .113 & 1.000 & -.418 & .562 \\
& Sup & .033 & -.418 & 1.000 & -.281 \\
& Prob & .883 & .562 & -.281 & 1.000 \\
\hline \multirow{5}{*}{ Sig. (1-tailed) } & Reading &. & .357 & .467 & .002 \\
& Glob & .357 &. & .132 & .073 \\
& Sup & .467 & .132 &. & .250 \\
\hline
\end{tabular}

Table 5 presents the values of the reading strategy categories (Global, Support, and Problem-solving strategies) toward reading achievement. It is presented that PROB (problem-solving strategies) category holds the highest value (.883) of correlational coefficient toward reading achievement. The SUP (support strategies) category is the lowest value of the correlational coefficient that is .033 toward reading achievement of the EFL students. Accordingly, it can be concluded that the higher the value of the problem-solving reading strategy categories, the higher the students' reading achievement would be. In other words, if the students applied problem-solving reading strategies in reading academic texts, their achievement in reading comprehension would be better.

\section{DISCUSSION}

Many studies have been conducted to investigate the use of reading strategies and its relationship with the reading ability among the students of English as a second language (ESL) context, but few studies examined the relationship between reading strategy use and reading ability among the students of English as a foreign language learning (EFL) setting. This study was conducted in order to find out the relationship between the use of reading strategies with the reading achievement of EFL students. It revealed that the EFL students were the high users of reading strategy use, accordingly they were termed as active strategic readers. This finding is in line with research findings conducted in EFL context by Nguyen \& Trinh (2011), Zhang \& Wu (2009), Abu-Snoubar (2017), and Al-Mekhlafi (2018) which indicate that the EFL students are generally strategic readers. Interestingly, this research finding also is similar to studies were conducted by Huang and Nisbet (2014), Madhumathi \& Ghosh (2012), and Poole (2009) in ESL context which reveals that the students are active users of reading strategies.

Moreover, in the context of overall strategy use, the students used medium to high-level reading strategy. Specifically, among the three subscales strategy categories, the 
students, in this study, favored problem-solving reading strategies, followed by global and support reading strategies. Interestingly, this research finding is consistently in categories order with the studies were conducted by Shang (2018), Hong-Nam (2014) and Sheorey \& Motkhtari (2001). Favoring on the problem solving strategies are trends among the research findings on investigating the relationship between the strategy use and the reading achievement of the ESL and EFL students (Huang \& Nisbet, 2014, Poole, (2013), Madhumathi \& Ghosh (2012), Nguyen \& Trinh (2011), Iwai \& Ramp (2011), Alsheikh \& Motkhtari, (2011), and Anderson (2003). These findings, unfortunately, a contrast to the research findings by Chen \& Chen (2015) which reveals the most reading strategy used by the EFL students was the global reading strategies, followed by problem-solving and support reading strategies. These distinctions are probably caused by certain factors, such as different research setting, the level of the readers' language proficiency, text difficulty, and learning styles. The most apparent factors influencing the differences are the level of the education and language proficiency of the subject in this study with the subject under Chen \& Chen's (2015) study. In Chen \& Chen's (2015) study, the participants were the high school students; meanwhile, in the current study, the participants were the university students. The level of language proficiency is also seen as a possible factor which influences the students' use of reading strategies. Huang \& Nisbet (2014) and Hong-Nam (2014) specify that level of language proficiency has a major effect on the strategies that the students use. In this study, the students who were majoring in English were explicitly trained to employ different reading strategies during their reading classroom activities. Furthermore, learning style is another possible aspect which triggers the difference of the reading strategy use. Phakiti (2003) indicate that individual characteristics may influence reading performance. This is because different readers in different cultural and language background may process the same text in different ways, depending on their purposes, attitudes, interests, and background knowledge. Thus, investigating on influencing of the level of education, level of language proficiency, learning styles, and individual differences as possible factors influencing the reading strategy use is crucial to be conducted by future researchers.

The finding of the study also reveals a statistically significant and positive relationship between the overall reading strategy use and the EFL students reading scores. Moreover, the correlation between the reading strategies and reading achievement was at a moderate level. This indicates that reading achievement was not merely contributed by the students' use of reading strategies. There are probably other factors influencing the students' reading achievement such as language proficiency (Huang and Nisbet, 2014), linguistic knowledge: vocabulary and grammatical knowledge (Zhang, 2012; Aryadoust \& Baghaei, 2016), and other factors, such as level of education, level of language proficiency, learning styles, and individual differences. Despite the moderate level of the relationships between the measured variables, the finding of this study incorporates other studies conducted by Hong-Nam (2014), Saeedeh (2013), Madhumathi \& Ghosh (2012), and Nguyen \& Trinh (2011). These findings indicate that the students are successful strategic readers which purposefully apply strategies to construct the meaning from the reading materials. Baker and Brown (1984) state that successful readers have 
an awareness and control of the cognitive activities they engage in as they read. This indicates that successful readers always employ reading strategies when reading texts. As Hong-Nam (2014) summed up his research found that readers who have higher use of reading strategies do well on reading test and perceived themselves as high in their reading ability. Accordingly, this finding suggests that the students, as the EFL learners, should be well trained in order to highly aware of their reading strategies use and consciously apply and control when reading academic texts. Interestingly, by contrast, this finding differs from the study conducted by Iwai \& Ramp (2011) who find no positive correlations were revealed between the students' academic performance and their scores on the SORS. This indicates that the students' use of reading strategies measured by SORS did not contribute to the students' academic success indicating by their grade point averages (GPA) in college. It is probably because the SORS is an instrument intended to measure adolescent and adult ESL/EFL students' metacognitive awareness and perceived use of reading strategies while reading academic materials such as textbooks (Mokhtari \& Sheorey, 2002). This specifies that the SORS is only applicable for measuring the students' use of reading strategies. Whereas, the students' academic success indicating by their GPA relates to their overall achievement over a certain period of time which covers all the subjects the students planned and acquired. However, this finding inspires the future studies to carefully examine the relationship between the use of reading strategies and the students' academic success indicating by GPA with putting into consideration of the validity and reliability of GPA scores as a measure of the students' academic achievement.

Relating to the research finding on strategy category which predicts the reading ability of the EFL students, it uncovers that problem solving is the most predictive reading strategy categories toward the students' reading achievement. Mokhtari and Sheorey (2002) explain that problem-solving strategies are "actions and procedures that readers use while working directly with a text. These are localized, focused techniques used when problems develop in understanding textual information; examples include adjusting one's speed of reading when the material becomes difficult or easy, guessing the meaning of unknown words, and rereading the text to improve comprehension". This finding is consistent with other studies (Huang \& Nisbet, 2014, Hong-Nam, 2014); however, it contradicts with the study by Saeedeh (2013) who find that only global reading strategy use could be a predictor of the students reading scores. This contradictory finding can be caused by many possible factors, including language and reading proficiency level, cultural setting, text difficulty, types of reading tasks, and the students' learning styles. However, as the implication of the study on the instructional site, these research findings advocate the teachers to teach students focusing on applying the problem-solving strategies in reading; it is because the problem-solving strategies category are beneficial for them in increasing their reading achievement.

Another interesting finding of the current research is that the support reading strategies (SUP) category are the least reading strategy categories used by EFL students when reading academic texts. This finding becomes the trends among the other studies by other researchers in different setting and time; and it confirms the studies by Zhang \& Wu (2009), Huang \& Nisbet (2014), Madhumathi \& Ghosh (2012), and Chen \& Chen 
(2015). These reading strategy categories are the least frequently used probably because of the students do not necessarily use a dictionary, take notes, underline information in the text, highlight textual information, translate the reading text into their first language, or read aloud as the support aids to tackle the content of the academic texts. As Mokhtari \& Sheorey (2002) state that support strategies are "basic support mechanisms intended to aid the reader in comprehending the text, such as using a dictionary, taking notes, underlining, or highlighting textual information". Intelligently, this study reveals that the EFL students guess the meaning of the unknown words or phrases from context as part of problem-solving strategies in reading, instead of using a dictionary to translate the meaning of the words into their first language. Moreover, the students also adjust their speed of reading, reread the text, and try to picture and visualize the information in the texts in order to help them understand the whole content of the texts. These strategies are problem-solving based which are useful and significantly contribute to their reading ability. Accordingly, the implication of the study for teaching reading is that the EFL students should be trained to apply problem-solving strategies in reading to empower their reading ability; and encouraging the students to put away of the dictionary while reading because it distracts their comprehension in reading the texts. Translating the texts into their first language should also be prohibited in academic reading because they cannot help the students to understand the content of the texts.

\section{CONCLUSION}

This study reveals that EFL students are active reading strategy users. This suggests that the teachers should create a situation where the students can apply the strategies in reading; it is because the students are already independently aware of using the strategies in reading academic texts and able to apply the strategy in reading. Moreover, the finding also shows the moderate correlation between the overall use of reading strategy and students' reading achievement. Accordingly, the more the students use of strategy in reading, the better their understanding of the text. More specifically, among the three reading categories (global, problem solving, and support strategies), the problem-solving categories are the most frequently used by the EFL students, and it is a predictive factor of increasing the students' reading achievement in the reading comprehension test (CRT). Thus, if the students apply problem-solving strategies in reading academic texts, their achievement in reading comprehension will be better.

The implications and recommendations of the study for teaching reading in an EFL setting. From an instructional perspective, this study indicates that the students are active users of reading strategies, therefore, the teachers should raise the students' awareness of the use of reading strategies in reading activities through explicit instruction of the use of reading strategies. Furthermore, the teachers should well educate and train the students to employ problem-solving strategies in constructing the meaning from the reading materials. This could be done through training the students to infer the unknown words or phrases from contexts, adjust their speed in reading when the texts are getting difficult, try to picture or visualize the information in the texts in order to comprehend the texts, and stop and think about the information while reading. Those strategies are reflected as a problem-solving based reading strategy which powerfully affects the students' reading achievement. Accordingly, the more the EFL 
students employ problem-solving strategies in reading activities, the better the comprehension they get from the texts.

The findings of this study also provide recommendations for future researchers. For example, in accordance of using reading strategies, the researchers may also investigate the influence of the level of education, level of language proficiency, learning styles as possible factors predicting the EFL students reading achievement. Furthermore, this study contains constraints in which the number of the participants involved was limited; thus, the future researchers may conduct the same research with the big number of participants.

\section{REFERENCES}

Abu-Snoubar, T. K. (2017). English as a foreign language learners' major and metacognitive reading strategy use at Al-Balqa Applied University. English Language Teaching, 10(9), 69-85.

Afflerbach, P., Pearson, P. D., \& Paris, S. G. (2008). Clarifying differences between reading skills and reading strategies. The Reading Teacher, 61(5), 364-373. Doi: 10.1598/RT.61.5.1.

Ahmadian, M., \& Pasand, P. G. (2017). EFL learners' use of online metacognitive reading strategies and its relation to their self-efficacy in reading. The Reading Matrix: An International Online Journal, 17(2), 117-132.

Al-Mekhlafi, A. M. (2018). EFL learners metacognitive awareness of reading strategies. International Journal of Instruction, 11(2), 297-308.

Alsheikh, N. O., \& Mokhtari, K. (2011). An examination of the metacognitive reading strategies used by native speakers of Arabic when reading in English and Arabic. English Language Teaching, 4(2), 151-160. doi: 10.5539/elt.v4n2p151.

Amiryousefi, M., Dastjerdi, H. V., \& Tavakoli, M. (2012). Iranian EAP students' reading strategy use and their beliefs about reading comprehension components: Toward an EAP reading model. World Applied Sciences Journal, 18(8), 1172-1179. DOI: 10.5829/idosi.wasj.2012.18.08.1156.

Anderson, N. J. (2003). Scrolling, clicking, and reading English: Online reading strategies in a second/foreign language. The Reading Matrix, 3(3), 1-33.

Aryadoust, V., \& Baghaei, P. (2016). Does EFL readers' lexical and grammatical knowledge predict their reading ability? insights from a perception artificial neural network study. Educational Assessment, 21(2), 135-156.

Ary, D., Jacobs, L. C., Sorensen, C., \& Razavieh, A. (2010). Introduction to research in education. Belmont: Cengage Learning.

Baker, L., \& Brown, A. L. (1984). Metacognitive skills and reading. In Pearson, P. D. (Ed.), Handbook of reading research. New York: Longman.

Barrot, J. S. (2016). ESL learners' use of reading strategies across different text types. The Asia-Pacific Edu. Researcher, 25(5), 883-892. DOI: 10.1007/s40299-016-0313-2. 
Chen, K. T., \& Chen, S. C. (2015). The use of EFL reading strategies among high school students in Taiwan. The Reading Matrix: An Int. Online Journal, 15(2), 156-166.

Creswell, J. W. (2012). Educational research: Planning, conducting and evaluating quantitative and qualitative research. Boston: Pearson Education.

Denton, C. A., Wolters, C. A., York, M. J., Swanson, E., Kulez, P. A, \& Francis, D. J. (2015). Adolescents' use of reading comprehension strategies: Differences related to reading proficiency, grade level, and gender. Learning and Individual Differences, 37, 81-95. Doi: 10.1016/j.lindif.2014.11.016.

Dole, J. A., Duffy, G. G., Roehler, L. R., \& Pearson, P. D. (1991). Moving from the old to the new: Research on reading comprehension instruction. Review of Educational Research, 61(2), 239-264. Doi: 10.3102/00346543061002239.

Duffy, G. G. (2009). Explaining reading: A resource for teaching concepts, skills, and strategies. New York: A Division of Guilford Publication Inc.

Dörnyei, Z. (2007). Research methods in applied linguistics. New York: Oxford U.

Gebhard, J. G. (2000). Teaching English as a foreign or second language. Ann Arbor: The University of Michigan Press.

Genc, H. (2011). Paper and screen reading strategies used by low-proficient EFL learners. English Teaching, 8(10), 648-658.

Hong-Nam, K. (2014). ELL high school students' metacognitive awareness of reading strategy use and reading proficiency. TESL-EJ, 18(1), 1-16.

Huang, J., \& Nisbet, D. (2014). The relationship between reading proficiency and reading strategy use: A study of adult ESL learners. J. of Adult Education, 43(2), 1-11.

Iwai, Y., Filce, H., \& Ramp, E. (2011). Academic English reading for international college students: The role of metacognitive reading strategies. Research in the Schools, 18(2), 75-88.

Khamkhong, S. (2018). Developing English L2 critical reading and thinking skills through the Pisa reading literacy assessment framework: A case study of Thai EFL learners. 3L: The Southeast Asian Journal of English Language Studies, 24(3), 83-94. http://doi.org/10.17576/3L-2018-2403-07.

Kim, H. (2016). The relationships between Korean university students' reading attitude, reading strategy use, and reading proficiency. Reading Psychology, 37(8), 1-34. Doi: 10.1080/02702711.2016.1193581.

Madhumathi, P., \& Ghosh, A. (2012). Awareness of reading strategy use of Indian ESL students and the relationship with reading comprehension achievement. English Language Teaching, 5(12), 131-140.

Manoli, P., \& Papadopoulou, M. (2012). Reading strategies versus reading skills: Two faces of the same coin. Procedia - Social and Behavioral Sciences, 45, 817-821.

Mokhtari, K., \& Reichard, C. A. (2002). Assessing students' metacognitive awareness of reading strategies. Journal of Educational Psychology, 94(2), 249-259. 
Mokhtari, K., \& Sheorey, R. (2002). Measuring ESL students' awareness of reading strategies. Journal of Developmental Education, 25(3), 2-10.

Muijselaar, M. M. L., Swart, N. M., Steenbeek-Planting, E. G., Droop, M., Verhoeven, L., \& de Jong, P. F. (2017). Developmental relations between reading comprehension and reading strategies. Scientific Studies of Reading, 21(3), 194-209. Doi: 10.1080/10888438.2017.1278763.

Nguyen, T. M. T., \& Trinh, L. Q. (2011). Learners' metacognitive strategy use and reading comprehension: Insights from a Vietnamese context. Journal on English Language Teaching, 1(1), 9-19.

Oxford, R. L., \& Burry-stock, J. A. (1995). Assessing the use of language learning strategies worldwide with the ESL/EF version of the strategy inventory for language learning (SILL). System, 23(1), 1-23. Doi: 10.1016/0346-251x(94)00047-a.

Ozek, E. \& Civelek, M. (2006). A study on the use of cognitive reading strategies by ELT students. The Asian EFL Journal, 14(1), 1-26.

Pinninti, L. R. (2016). Metacognitive awareness of reading strategies: An Indian context. The Reading Matrix: An International Online Journal, 16(1), 179-193.

Poole, A. (2013). Fiction reading strategies of college readers. Journal of College Reading and Learning, 43(2), 91-109.

Poole, A. (2009). The reading strategies used by male and female Colombian university students. PROFILE, 11, 29-40.

Sadeghi, N., Kasim, Z. M., Tan, B. H., \& Abdullah, F. S. (2012). Learning styles, personality types and reading comprehension performance. English Language Teaching, 5(4), 116-123.

Saeedeh, K.K. (2013). Does reading strategy use predict and correlate with reading achievement of EFL learners? International Journal of Research Studies in Language Learning, 2(2), 29-38.

Shang, H. (2018). EFL medical students' metacognitive strategy use for hypertext reading comprehension. Journal of Computing in Higher Education, 30(2), 259-278. Doi: http://doi.org/10.1007/s12528-017-9156-y.

Shih, H. J., \& Huang, S. C. (2018). EFL learners' metacognitive strategy use in reading tests. English Teaching \& Learning, 42(2), 117-130. Doi: 10.1007/s42321-018-0007-3.

Sulistyo, G. H. (2015). Reading for meaning: Theories, teaching strategies, and assessment. Malang, Indonesia: Pustaka Kaiswaran.

Zhang, L. J. \& Wu, A. (2009). Chinese senior high school EFL Students' Metacognitive Awareness and Reading-Strategy Use. Reading in a Foreign Language, 21(1), 37-59.

Zhang, D. (2012). Vocabulary and grammar knowledge in second language reading comprehension: A structural equation modelling study. The Modern Language Journal, 96(4), 558-575. 